\title{
EVALUATION OF KNOWLEDGE- ATTITUDE- PRACTICE (KAP) OF INTERN DENTISTS IN EMERGENCY MANAGEMENT OF TRAUMATIC DENTAL INJURIES IN PERMANENT ANTERIOR TEETH (A CROSS-SECTIONAL STUDY)
}

\author{
Nada M. Shaheen*, Nevine G. Waly ${ }^{* *}$ and Manal A. El-Sheikh***
}

\begin{abstract}
Background: This cross sectional study aimed to evaluate Egyptian intern dentist's knowledge, Attitude and Practice in emergency management of traumatic dental injuries in permanent anterior teeth.

Materials and Methods: A four-part questionnaire was distributed among 500 intern dentists. Part 1 consisted of 8 questions focusing on personal and professional information, part 2 consisted of 3 close-ended questions and the $4^{\text {th }}$ question was a case which included 9 close-ended questions related to the case, Part 3 consisted of 9 close-ended questions to assess the attitude of intern dentists, and part 4 consisted of 4 close-ended questions related to assessment of practice of intern dentists regarding traumatic dental injuries in permanent anterior teeth in children .The data were analyzed using the t-test at $\mathrm{P}<0.05$ level of confidence.
\end{abstract}

Results: A total of 500 intern dentists participated in the survey, 235 (47\%) were males and 265 $(53 \%)$ were females. The overall mean age was $23.6 \pm 1.3$ years. The mean value of knowledge scores was $4.37 \pm 1.45$. There was no statistically significant correlation between knowledge score of intern dentist and ability to provide proper action when needed.

Conclusion: The knowledge of intern dentists regarding the management of traumatic dental injuries in permanent anterior teeth was inadequate.

KEYWORDS: Traumatic dental injuries, Dental trauma, Dental emergency, permanent anterior teeth, young immature permanent teeth

\footnotetext{
* Teacher Assistant in the Faculty of Pediatric Dentistry, MSA University

** Professor of Pediatric Dentistry and Dental Public Health, Faculty of Dentistry, Cairo University

*** Associate Professor of Pediatric Dentistry and Dental Public Health, Faculty of Dentistry, Cairo University
} 


\section{INTRODUCTION}

Traumatic dental injuries (TDIs) in children and adolescents are a common problem. Patients suffering from TDIs are affected both physically and psychologically (Çınar et al., 2013). In permanent teeth, there are many variations in the types of injuries according to type and severity of the trauma. Trauma can affect both soft and hard tissues, it also affects the pulp, periodontal ligament, and gingiva and may lead to pathological root resorption or incomplete root formation (Niviethitha et al., 2018).

The dentist's knowledge regarding TDIs leading to avulsion is critical for the prognosis of traumatized teeth as it occurs when the dentists are least prepared. Thus, a prompt and standard management of TDIs can improve the case prognosis as well as reduce stress and anxiety in patients, their parents, and the dentist concerned (Mustafa Ali et al., 2019). Therefore, it is of prime importance for the general practitioners to have well-grounded knowledge about the various presentations of dental traumatic injuries, the clinical techniques to diagnose it and proper management of such conditions (Nandakumar \& Nasim, 2017). The experience level of the dental interns was based on educational programs, previous knowledge, experience, and the months of internship period ( Limbu et al., 2014).

This study assessed the level of knowledge gap regarding knowledge, attitude and practice of management of dental traumatic injuries in permanent teeth among intern dentists.

\section{MATERIALS AND METHODS}

Five hundred intern dentists were randomly selected from two universities, Faculty of DentistryCairo University and Modern Science and Arts (MSA) University. The subjects were asked to fill out a self-administered questionnaire. The questionnaires were collected over an 8 month period starting from July 2018 till February 2019.
The data was collected by means of a structured questionnaire, which was modified from those used in previous studies by Raoof et al., 2012 and Cinar et al., 2013. The questionnaire was formed of 4 parts. Part 1 included 8 questions focusing on personal and professional information like age, gender, year and university of graduation, and their previous training experiences, background knowledge and if their education was enough to deal with traumatic dental injuries or not. Part 2 consisted of 3 close-ended questions (multiple choice) and the $4^{\text {th }}$ question was a case of avulsion which included 9 close-ended questions related emergency management of avulsion, time required to seek professional help and storage media. Part 3 consisted of 9 close-ended questions to assess the attitude of intern dentists, and finally Part 4 questions were related to assessment of practice of intern dentists regarding traumatic dental injuries in permanent anterior teeth in children.

The data was analyzed using statistical analysis software SPSS version 20. The Student's t-test and one-way ANOVA were used to compare the knowledge of intern dentists about different aspects of traumatic events. The difference between male and female intern dentists was assessed by student's $t$-test. P value $<0.05$ which was considered significant.

\section{RESULTS}

500 questionnaires were completed and returned by 265 females and 235 males with mean age of the intern dentist $23.6 \pm 1.3$ years old (22-27 age range). 258 (52\%) intern dentists who had graduated from Cairo University, and 242 (48\%) intern dentists who had graduated from MSA University, Most of the interns graduated in 2018 (79.9\%), while few of them graduated in 2017 (19.6\%), and only five interns graduated in $2016(1 \%)$. Participants' knowledge about the clinical management of traumatic dental injuries and the mean knowledge 
score (Part II) are summarized in Table 1, Figures $(1 \& 2)$. Regarding Attitude and practice of participants (Part III \& IV), 490 (98\%) intern dentists agreed that time consciousness for management of dental trauma could play vital role in improving the prognosis, 403 (82\%) intern dentists claimed they hadn't attempted to manage an emergency case of traumatic dental injuries before.

The total mean knowledge score was $4.37 \pm 1.45$. There was a high statistically significant correlation between knowledge score and University of graduation $(P=0.055)$. There was no statistically significant correlation between knowledge score and previous training of interns as dental assistants in clinics $(P=0.847)$. The relationship between ability to provide proper action when needed and knowledge score was insignificant $(P=0.788)$. The need for future education regarding dental trauma had insignificant effect on the knowledge score as well $(P=0.979)$.

TABLE (1) The part in the questionnaire focusing on the knowledge of intern dentists on traumatic dental injuries and frequency $(\%)$ of the answers

\begin{tabular}{|c|c|c|}
\hline Questions & Answers & Frequency $(\%)$ \\
\hline $\begin{array}{l}\text { If an immature permanent maxillary tooth } \\
\text { has been intruded, the tooth should be? }\end{array}$ & $\begin{array}{l}\text { Left for spontaneous re-eruption } \\
\text { Repositioned orthodontically } \\
\text { Repositioned surgically } \\
\text { Extracted immediately } \\
\text { Don't know }\end{array}$ & $\begin{array}{l}303(61 \%) \\
122(25 \%) \\
36(7 \%) \\
16(3 \%) \\
22(4 \%)\end{array}$ \\
\hline $\begin{array}{l}\text { If you decide to replant the tooth back in } \\
\text { its socket in case of avulsed tooth, but it } \\
\text { has fallen onto the ground and was covered } \\
\text { with dirt, what would you do? }\end{array}$ & $\begin{array}{l}\text { Scrub the tooth gently with a tooth brush } \\
\text { Rinse the tooth under tap water } \\
\text { Put the tooth straight back into the socket without } \\
\text { doing anything } \\
\text { Others (antiseptic/ alcohol) } \\
\text { Don't know }\end{array}$ & $\begin{array}{l}57(11 \%) \\
333(67 \%) \\
13(3 \%) \\
68(14 \%) \\
27(5 \%)\end{array}$ \\
\hline Knowledge score & $\begin{array}{l}1 \\
12\end{array}$ & $\begin{array}{l}1(0.2 \%) \\
5(1 \%)\end{array}$ \\
\hline
\end{tabular}

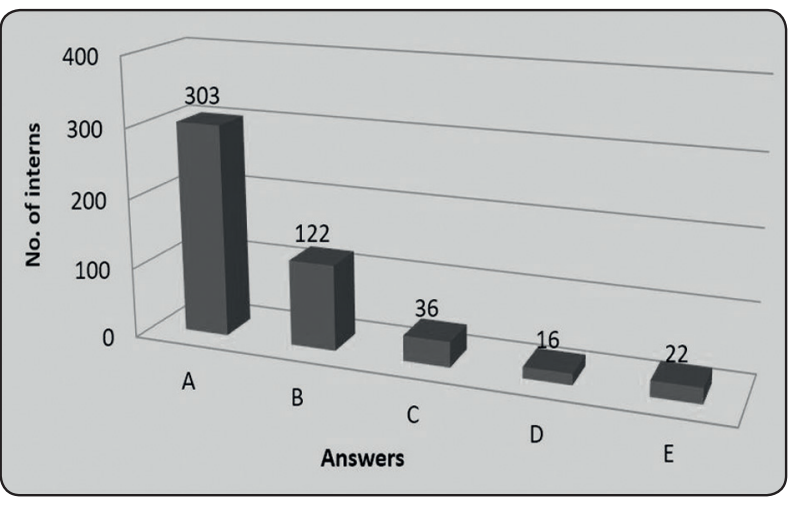

Fig. (1) Column chart regarding treatment of choice for anterior maxillary permenant tooth intrusion in the study sample

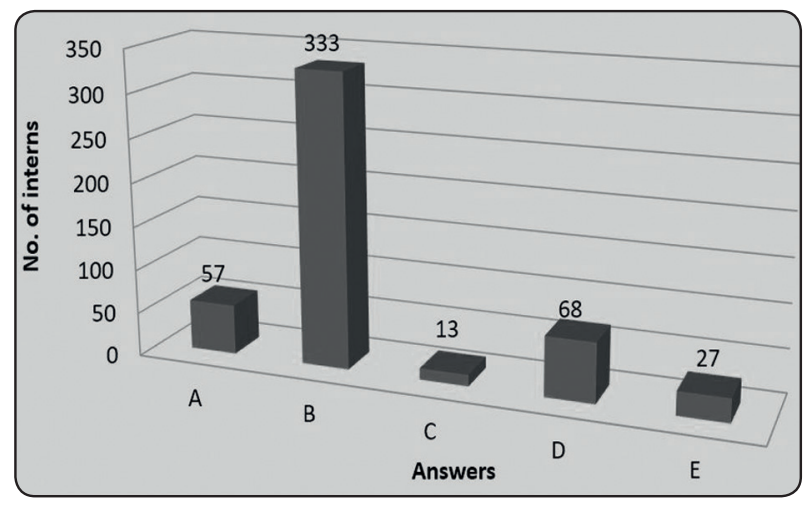

Fig. (2) Column chart regarding the immediate action taken if the tooth intended for re implantation fell in dirt in the case 


\section{DISCUSSION}

The results in the present study showed that $(64 \%)$ intern dentists had previous training as dental assistants in clinics, (47\%) intern dentists thought they had enough knowledge in dental emergency management, S Limbu et al., 2014, Al-Shamiri et al., 2015, and Hartmann et al., 2019 studies showed higher percentage $(95 \%, 65 \%$, and $61 \%$ respectively).This difference in findings may be due to of the fact that most of the dental interns had attended an educational program regarding traumatic injuries. Also (95\%) intern dentists thought they needed future education regarding dental emergency management, while (67\%) intern dentists thought they were able to provide proper action when needed.

According to the results in this study (24\%) intern dentists agreed that pulpotomy is the treatment of choice for a large pulp exposure of an immature permanent tooth after more than 24 hours of trauma. This result showed that the knowledge of intern dentists was inadequate when compared to the results in the study by Akhlaghi et al, 2014 where the results of that study suggested that dentists' knowledge was acceptable regarding the treatment of this emergency. This is due to the lack of exposure to TDIs clinical cases and lack of guidance and practice.

As regards to this study (77\%) intern dentists agreed that the time required to seek professional help of an avulsed permanent tooth was within the first 30 minutes, this result was similar to findings in other studies Cohenca et al., 2006 and Zhao \& Gong, 2010 where immediate replantation was chosen by the majority of dental practitioners due to the knowledge gained from undergraduate programs and the information available on the internet as well as the high awareness level. Also (53\%) intern dentists agreed that the 8 year old boy with avulsed upper front permanent tooth should be admitted to a dental hospital after first contact, and this agreed with the Guidelines for the management of traumatic dental injuries of permanent teeth by Andersson et al., 2018.

The knowledge regarding cleaning the avulsed permanent tooth, (67\%) intern dentists chose to rinse the tooth gently under running tap water without scrubbing and putting it back into socket. This result agreed with a study by Limbu et al., 2014, but better than study by Fujita et al., 2014 in which (55.4\%) students answered correctly. Difference in the results may be related to the prior knowledge of the interns about management of avulsed teeth, and attendance of educational programs regarding traumatic dental injuries to teeth. While the general knowledge of intern dentists regarding storage medium of the avulsed permanent tooth was perfect where $96 \%$ of them chose milk or saliva as storage media. Which suggests that the intern dentists had adequate knowledge regarding the appropriate storage media. That study had better results than a previous study by Alaslami et al., 2018 where (60\%) of the general dentist participants preferred milk or saliva as storage media, indicating that they knew milk and saliva were the most practical transport mediums for the storage of avulsed teeth because $\mathrm{PH}$ and osmolality of them were similar to those of extracellular fluid. The high awareness level of storage media was attributed to the knowledge gained from the undergraduate curriculum.

Majority of the intern dentists (98\%) agreed that time is important for the prognosis of the traumatized tooth, and regarding the management of TDI's (93\%) intern dentists believed that they required special education and training. Moreover (96\%) intern dentists agreed that management of dental trauma must become one of the educational priorities for intern dentists and must be included as part of their teaching curriculum to improve their knowledge, (95\%) intern dentists were interested in 
attending an educational program on dental trauma management.

Regarding the assessment of practice concerning TDI's, (82\%) intern dentists reported that they hadn't previously attempted to manage emergency cases of TDIs. This result came in agreement with a previous study by Akhlaghi et al., 2014 where the majority of participants declared that they rarely encountered traumatic events in their daily practice, which was consistent with the results of other studies Garcia et al., 2000 \& Krastl et al., 2009 indicating that TDIs occurred infrequently and at occasions when practitioners were not prepared for their appropriate management. The most common cases the intern dentists attempted to manage were luxation cases (36\%). (59\%) intern dentists wrote that they would attempt to replant an avulsed tooth. This result came in agreement with a study by Fujita et al.,2014 who showed that $(60.3 \%)$ dental students would attempt to replant an avulsed tooth. However, the results contradicted the results of Melo \& Couto, 2016 who reported that $(81.31 \%)$ of graduated dental students never treated an avulsed case.

In case of replantation of an avulsed tooth, $(65 \%)$ intern dentists stated they would prescribe antibiotics, this result was in contrast to results of a previous study by Cinar et al., 2013, where nearly all dentists (94.8\%) prescribed antibiotics in cases of avulsion injuries. Regarding the type of splint preferred, (52\%) intern dentists stated they would use stainless-steel wire in splinting of avulsed teeth, that result agreed with a previous study by Limbu et al., 2014 where (46\%) intern dentists correctly answered that a flexible splint should be used after replantation of an avulsed permanent tooth to allow physiologic movement of the tooth during healing.

In the present study there was a high statistically significant correlation between knowledge score and University of graduation $(P \leq 0.000)$. Regarding the previous training, there is no statistically significant correlation between knowledge score of intern dentists with and without previous training as dental assistants in clinic $(P>0.05)$. The relationship between the ability to provide proper action when needed and knowledge score was insignificant $(P>0.05)$. These findings are in agreement with previous study done by Emhemmed, 2017. The need for future education regarding dental trauma had a statistically significant effect on the knowledge score $(P \leq 0.05)$. These findings came in agreement with a previous study done by Akhlagi et al., 2014 .

\section{CONCLUSION}

The present study showed adequate level of knowledge and practice of intern dentists in managing emergency cases of TDIs. The study also showed inadequate level of knowledge regarding appropriate treatment of intruded permanent tooth and prescription of antibiotic therapy as well as Practice regarding attempts to manage emergency cases of TDIs and prescription of antibiotics in case of replanting an avulsed tooth. High positive attitude of intern dentists towards early intervention in management of traumatic dental injuries was recorded.

\section{REFERENCES}

1. Akhlagi N, Nourbakhsh N, Khademi A, Karimi L. (2014) General Dental Practitioners' Knowledge about the Emergency Management of Dental Trauma, IEJ Iranian Endodontic Journal, 9 (4), pp.251-256.

2. Al-Shamiri, H.M., Alaizari, N.A., Al-Maweri, S.A. \& Tarakji, B. (2015) Knowledge and attitude of dental trauma among dental students in Saudi Arabia. European Journal of Dentistry, 9(4), pp.518-522.

3. Alaslami, R.A., Elshamy, F.M.M., Maamar, E.M. \& Ghazwani, Y.H. (2018) Awareness about management of tooth avulsion among dentists in Jazan, Saudi Arabia. Open Access Macedonian Journal of Medical Sciences, 6 (9), pp.1712-1715.

4. Andersson, L., Andreasen, J.O., Day, P., Heithersay, G., Trope, M., DiAngelis, A.J., Kenny, D.J., Sigurdsson, A., 
Bourguignon, C., Flores, M.T., Hicks, M.L., Lenzi, A.R., Malmgren, B., Moule, A.J. \& Tsukiboshi, M. (2018) Guidelines for the management of traumatic dental injuries: 2. Avulsion of permanent teeth. Pediatric Dentistry, 40 (6), pp.424-431.

5. Cinar C, Atabek D, Alaçam A. (2013) Knowledge of dentists in the management of traumatic dental injuries in Ankara, Turkey. Oral Health Prev Dent,11 pp.23-30

6. Cohenca, N., Forrest, J.L. \& Rotstein, I. (2006) Knowledge of oral health professionals of treatment of avulsed teeth. Dental Traumatology, 22 (6), pp.296-301.

7. Emhemmed S.A. (2017) Thesis: Evaluation of Knowledge- Attitude- Practice (KAP) of intern dentists in emergency management of Traumatic Dental Injuries. 1(1) pp.1-81

8. Fujita, Y., Shiono, Y. \& Maki, K. (2014) Knowledge of emergency management of avulsed tooth among Japanese dental students. BMC Oral Health, 14 (1), pp.1-6.

9. Garcia-Godoy F, Pulver F. (2000) Treatment of trauma to the primary and young permanent dentitions. Dent Clin North Am. 44(3) pp.597-632.

10. Hartmann, R.C., Rossetti, B.R., Siqueira Pinheiro, L., Poli de Figueiredo, J.A., Rossi-Fedele, G., S. Gomes, M. \& Gutierrez de Borba, M. (2019) Dentists' knowledge of dental trauma based on the International Association of Dental Traumatology guidelines: A survey in South Brazil. Dental Traumatology, 35 (1), pp.27-32.

11. Krastl, G., Filippi, A. \& Weiger, R. (2009) German general dentists' knowledge of dental trauma. Dental Traumatology, 25 (1), pp.88-91.

12. Limbu, S., Dikshit, P., Bhagat, T. \& Mehata, S. (2014) Knowledge of dental interns towards emergency manage- ment of avulsed tooth in dental colleges in Nepal. Journal of Nepal Health Research Council, 12 (26), pp.1-7.

13. Melo, T. \& Couto, C.M. (2016) Evaluation of graduate dental students' knowledge on the therapeutic approach of dental avulsion. Rsbo, 12 (1), pp.23.

14. Mustafa Ali, M., Al Zoubi, L., Eissa, M. \& Splieth, C.H. (2019) Changes in the epidemiology and aetiology of dental traumatic injuries in permanent teeth in children before and after German unification. European Archives of Paediatric Dentistry, 20 (1), pp.41-46.

15. Nandakumar, M. \& Nasim, I. (2017) Nandakumar and Nasim: KAP survey on dental traumatic injuries. Journal of Advanced Pharmacy Education \& Research, 7 (2), pp.46-47.

16. Niviethitha, S., Bhawarlal, C., Ramkumar, H., Dhakshanamoorthy, S. \& Shanmugam, H. (2018) Effectiveness of an audio-visual aid on the knowledge of school teachers regarding the emergency management of dental injuries. Dental Traumatology, 34 (4), pp.290-296.

17. Raoof, M., Zaherara, F., Shokouhinejad, N. \& Mohammadalizadeh, S. (2012) Elementary school staff knowledge and attitude with regard to first-aid management of dental trauma in Iran: A basic premise for developing future intervention. Dental Traumatology, 28 (6), pp.441-447.

18. Zhao, Y. \& Gong, Y. (2010) Knowledge of emergency management of avulsed teeth: A survey of dentists in Beijing, China. Dental Traumatology, 26 (3), pp.281-284. 